\title{
PENGARUH VARIASI WAKTU DAN KECEPATAN PENGADUKAN DALAM PEMBUATAN ETIL ESTER DARI MINYAK KELAPA
}

\section{[The Effect of Variations in Reaction Time and Stirring Speed of Ethyl Ester Produced from Coconut Oil]}

\author{
Jusman $^{1^{\star}}$, Bambang Setiaji ${ }^{2}$, Triyono ${ }^{2}$, Akhmad Syoufian $^{2}$ \\ 1) Jurusan Kimia, Fakultas MIPA, Universitas Tadulako \\ Jl. Soekarno Hatta, Kampus Bumi Tadulako Tondo Palu, Telp. 0451- 422611 \\ 2) Jurusan Kimia, Fakultas MIPA, Universitas Gadjah Mada \\ Sekip Utara Kotak Pos 21 BLS Yogyakarta 55281
}

*)Corresponding Author: jusman_palu04@yahoo.com (+62852 4109 5775)

Diterima 31 Maret 2018, Disetujui 28 April 2018

\begin{abstract}
The objective of this research is to obtain optimum ethyl ester. This research was initiated by the transesterification reaction between coconut oil and ethanol with variations in reaction time and stirring speed. Ethyl ester was analyzed by GC (Gas Chromatography) and GC-MS (Gas Chromatography-Mass Spectroscopy). The optimum transesterification result of $76.48 \%$ was obtained at the ratio of oil/ethanol/NaOH 1: 2: $0.02(100 \mathrm{~mL}: 50 \mathrm{~mL}: 2 \mathrm{~g})$ with stirring speed of 300 $\mathrm{rpm}$. The stirring speed and reaction time in a row above $400 \mathrm{rpm}$ and 30 minutes wich produced yield of ethyl ester above $80 \%$.
\end{abstract}

Keywords: coconut oil, transesterification, reaction time and stirring speed

\begin{abstract}
ABSTRAK
Penelitian ini bertujuan memperoleh etil ester yang optimum. Penelitian ini diawali dengan reaksi transesterifikasi antara minyak kelapa dan etanol dengan variasi waktu dan kecepatan pengadukan. Etil ester dianalisis dengan GC dan GC-MS. Hasil transesterifikasi optimum sebesar $76,48 \%$ diperoleh pada rasio minyak kelapa/etanol/NaOH 1:2:0,02 (100 mL : $50 \mathrm{~mL}: 2 \mathrm{~g})$ dengan kecepatan pengadukan $300 \mathrm{rpm}$. Kecepatan pengadukan dan waktu reaksi berturut-turut di atas $400 \mathrm{rpm}$ dan 30 menit menghasilkan rendamen etil ester di atas $80 \%$.
\end{abstract}

Kata Kunci : minyak kelapa, transesterifikasi, variasi waktu, dan kecepatan pengadukan 


\section{LATAR BELAKANG}

Reaksi transesterifikasi merupakan reaksi kesetimbangan antara senyawa ester dengan alkohol (Gambar 1) dengan menggunakan katalis kimia ataupun enzimatik (Schuchardt et al., 1998).

$\mathrm{RCOOR}+\mathrm{R}^{\prime \prime} \mathrm{OH} \stackrel{\text { katalis }}{\rightleftharpoons} \mathrm{RCOOR}+\mathrm{R}^{\prime} \mathrm{OH}$

Gambar 1 Persamaan umum untuk reaksi transesterifikasi

Senyawa ester yang umumnya terlibat pada reaksi transesterifikasi adalah tirgliserida atau disebut juga minyak atau lemak. Minyak nabati sering digunakan dalam reaksi ini dengan bantuan katalis asam atau basa kuat yang selanjutnya menghasilkan alkil ester asam lemak dan gliserol (Gambar 2).

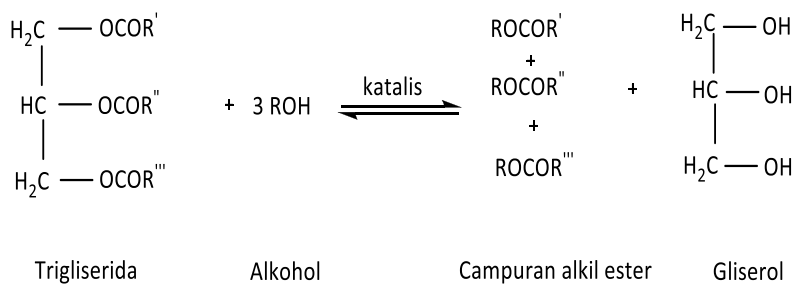

Gambar 2 Transesterifikasi minyak nabati (Fukuda et al., 2001)

Reaksi transesterifikasi melewati tiga tahapan, salah satunya adalah tebentuknya senyawa antara berupa mono dan digliserida (Freedman et al., 1986) Secara stoikiometris reaksi akan berlangsung sempurna jika terdapat $1 \mathrm{~mol}$ trigliserida dan $3 \mathrm{~mol}$ alcohol atau dengan kata lain perlu penggunaan alkohol berlebih agar reaksi berjalan kearah produk dan tentunya akan meningkatkan hasil alkil ester yang terbentuk
(Schuchardt et at., 1998). Adapun aspek yang berpengaruh dalam proses transesterifikasi antara lain: 1) jenis dan konsentrasi katalis (asam atau basa); 2) rasio molar alkohol/minyak; 3) suhu ; dan 4) pengadukan. Selain itu, pada reaksi ini reaktan harus terbebas dari kandungan air dan asam lemak bebas untuk menghindari terbentuknya sabun (Schuchardt et al., 1998).

Penelitian tentang faktor yang mempengaruhi transesterifikasi telah banyak dilakukan, diantaranya Freedman et al. (1984) mempelajari transesterifikasi minyak nabati dengan rasio molar metanol/ minyak ( $6: 1$ ), katalis $\mathrm{NaOH} 1 \%$, pada suhu 32,45 , dan $65^{\circ} \mathrm{C}$ membutuhkan waktu 0, 1 jam untuk mencapai konversi ester masing-masing 64, 87, dan 94 \%. Freedman et al. (1986) menyatakan bahwa penggunaan $\mathrm{CH}_{3} \mathrm{ONa}$ dalam metanolisis meskipun dalam konsentrasi yang rendah $0,5 \%$ memberikan hasil (98\%) dengan waktu reaksi yang singkat (30 menit). Meneghetti et al. (2006) melaporkan bahwa tingkat konversi etil ester tinggi diperoleh ketika reaksi dilakukan pada $80^{\circ} \mathrm{C}$ dengan rasio molar alkohol : minyak : katalis (60: 10 : 2), katalis asam dilaporkan memberikan laju reaksi rendah dibandingkan dengan katalis basa. Cernoch et al. (2010) mempelajari distribusi etil ester, gliserida, dan gliserol dari etanolisis minyak lobak dengan menggunakan katalis $\mathrm{KOH}$, waktu reaksi berada pada kisaran 1,5 -2 jam 
memberikan hasil $97 \%$ etil ester , sedang gliserol 0,29 \%. Kucek et al. (2007) menyatakan bahwa proses etanolisis dari minyak kedelai yang dimurnikan menggunakan katalis $\mathrm{NaOH}$ dan $\mathrm{KOH}$, rasio molar etanol : minyak (6:1 dan 12 : 1), konsentrasi katalis $\mathrm{NaOH} 0,3 \%$ dan $\mathrm{KOH} 1 \%$ pada suhu 30 dan $70{ }^{\circ} \mathrm{C}$, hasil analisis menunjukkan konversi ester 97,2 $\%$ diperoleh pada kondisi rasio molar 12 : 1 , suhu $70{ }^{\circ} \mathrm{C}$, dan katalis $\mathrm{NaOH} 0,3 \%$, sedangkan katalis $\mathrm{KOH} 1 \%$ pada kondisi yang sama konversi etil ester 95,6 \%.

Tippayawong et al. (2005) mempelajari proses optimasi produksi etil ester dari minyak kedelai (FFA 1\%) melalui central composite design, hasil analisis menunjukkan konversi etil ester 93\% dicapai pada kondisi rasio molar etanol : minyak (10.5 : 1), suhu $70^{\circ} \mathrm{C}$ dan konsentrasi katalis $\mathrm{NaOH} 1 \%$. Zhou et al. (2003) mempelajari pengaruh rasio molar alkohol/minyak, konsentrasi basa, dan suhu pada proses etanolisis minyak bunga matahari dan kanola. Hasil analisis menunjukkan bahwa konversi etil ester 99 \% diperoleh pada kondisi rasio molar etanol/minyak $30: 1$, katalis $\mathrm{KOH} 1,4 \%$, suhu $23{ }^{\circ} \mathrm{C}$ dengan waktu reaksi 15 menit.

\section{METODE PENELITIAN}

\section{Bahan dan Peralatan}

Bahan yang digunakan dalam penelitian ini adalah sebagai berikut: minyak kelapa diambil dari PT. Tropica Nucifera Indonesia, bahan lain seperti etanol, natrium hidroksida, asam klorida, dan natrium sulfat anhidrat.

Alat yang digunakan dalam penelitian ini yaitu peralatan gelas standar yang biasa dipakai di laboratorium, selain itu juga digunakan peralatan pendukung seperti mesin pengaduk merek RW 16 basicIKAWERKE (propeller stirrer), sedangkan peralatan analisis terdiri dari : Gas Chromatography (GC) merek Hewlett Packard 5890 series II (Kolom : RTX5100- ; Oven : 100-2-8-280 ; Carier : $\mathrm{H}_{2}$ $40 \mathrm{ml} /$ menit ; injektor : 280 'C, split $75 \mathrm{Kpa}$, injeksi: 0,5ul ; Detektor : FID (Flame Ionitation Detector) 290'C, Gas Chromatography-Mass Spectroscopy (GC-MS QP2010S Shimadzu Kolom: Rastek RXi-5MS, panjang: $30 \mathrm{~m}$, diameter dalam: 0,25 mm, temperatur oven: $100{ }^{\circ} \mathrm{C}$; Pengion: El (Electron Impact) digunakan untuk mengetahui kandungan komponen organik dan massa relatif dari komponen organik (Laboratorium Kimia Organik FMIPA UGM).

\section{PROSEDUR KERJA}

\section{Preparasi Sampel}

Sintesis etil ester asam lemak minyak kelapa dilakukan dalam reaktor berpengaduk kapasitas 2 liter. Untuk mendapatkan kondisi produksi yang menghasilkan etil ester asam lemak maksimum, diterapkan perlakuan pengaruh agitasi pengaduk dan waktu reaksi terhadap etil ester asam lemak yang dihasilkan. 
Pengaruh agitasi pengaduk (Jusman et al., 2013)

Kajian pengaruh agitasi pengaduk terhadap etil ester asam lemak yang terbentuk dilakukan menggunakan bahan baku minyak kelapa yang dihasilkan pada tahap penelitian sebelumnya. Komposisi reaksi etanolisis yakni rasio etanol/minyak kelapa/NaOH 1:2: 0,02. Agitasi pengaduk yang diterapkan masing-masing 200 rpm (A), $300 \mathrm{rpm}$ (B), $400 \mathrm{rpm}$ (C), $500 \mathrm{rpm}$ (D), dan 600 rpm (E). Reaksi berlangsung di dalam reaktor berpengaduk pada suhu ruang selama 60 menit. Reaksi dihentikan dengan asam klorida $6 \mathrm{M}$, kemudian gliserol dan sisa etanol dipisahkan dalam corong pemisah. Produk reaksi bebas etanol dan gliserol dilewatkan pada natrium sulfat anhidrat untuk membebaskan air yang terikut, kemudian ditentukan etil ester asam lemak yang terbentuk menggunakan metode gas kromatografi (GC). Agitasi pengaduk yang menghasilkan etil ester asam lemak

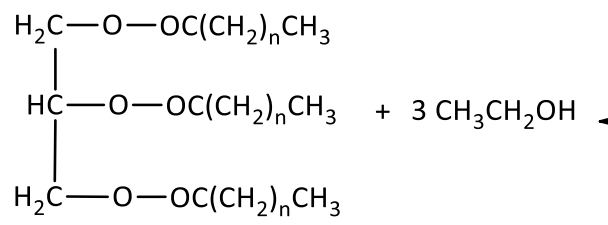

Minyak kelapa

Etanol maksimum, digunakan pada penelitian tahap selanjutnya.

\section{Pengaruh waktu reaksi}

Kajian pengaruh waktu reaksi terhadap etil ester asam lemak dilakukan dengan menerapkan waktu reaksi antara 20 sampai 60 menit. Pelaksanaan reaksi mengikuti cara sebelumnya dengan menggunakan agitasi pengaduk terbaik hasil penelitian sebelumnya. Parameter yang diamati adalah sama dengan sebelumnya. Waktu reaksi yang menghasilkan etil ester asam lemak maksimum digunakan pada penelitian selanjutnya.

\section{HASIL DAN PEMBAHASAN}

Pada penelitian ini dilakukan transesterifikasi antara minyak kelapa murni dan etanol menggunakan katalis natrium hidroksida (Gambar 3). Hasil reaksi transesterifikasi menghasilkan campuran etil ester asam lemak.

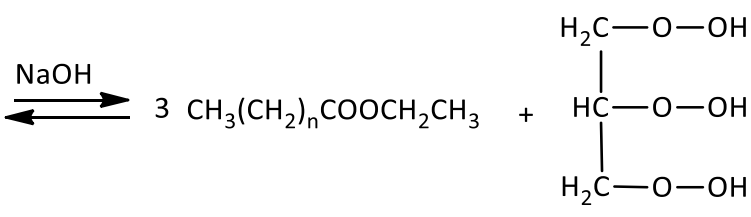

Campuran etil ester

Gliserol

Gambar 3 Reaksi transesterifikasi minyak kelapa

Pada tahapan awal reaksi saat $\mathrm{NaOH}$ dilarutkan dalam etanol akan terbentuk $\mathrm{Na}-\mathrm{OCH}_{2} \mathrm{CH}_{3}$. Di mana gugus etoksi $\left(-\mathrm{OCH}_{2} \mathrm{CH}_{3}\right)$ merupakan nukleofil kuat yang akan menyerang karbon karbonil trigliserida minyak kelapa serta merubah trigliserida menjadi campuran etil esternya (Gambar 4). 

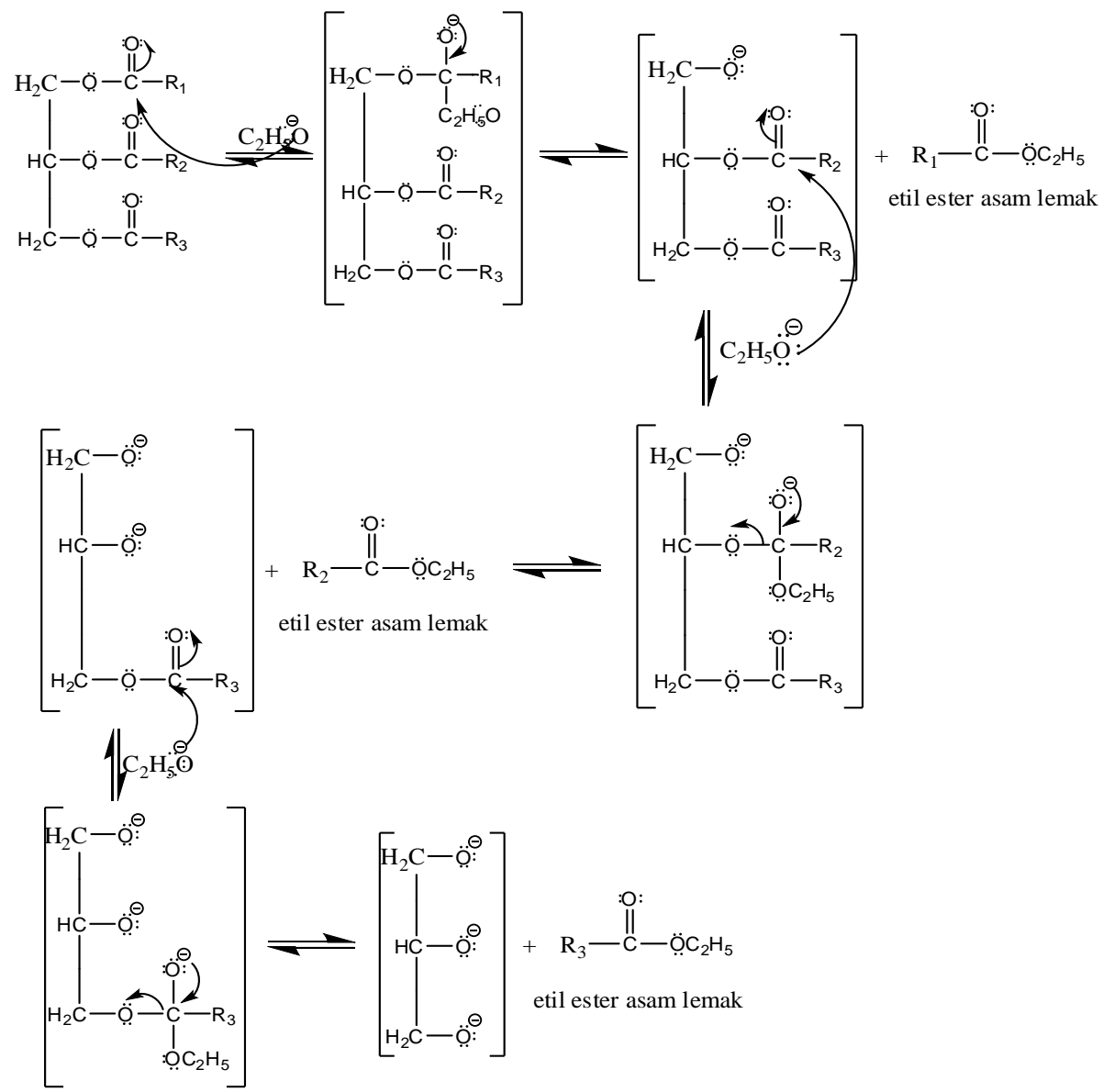

Gambar 4. Mekanisme reaksi transesterifikasi minyak kelapa dengan etanol

Proses transesterifikasi dilakukan dengan menambahkan minyak kelapa murni $100 \mathrm{~mL}$ ke dalam $50 \mathrm{~mL}$ etanol, katalis $\mathrm{NaOH} 2$ gram, berlangsung selama 60 menit pada suhu ruang, dan agitasi dilakukan dengan kecepatan pengadukan 300 rpm. Adapun rendamen campuran etil ester yang dihasilkan 76,48 \%. Berdasarkan hal tersebut rendahnya rendamen etil ester yang dihasilkan kemungkinan disebabkan oleh adanya air dalam etanol, serta kandungan asam lemak bebas dalam minyak. Keberadaan air akan menyebabkan terjadinya reaksi hidrolisis sehingga etil ester yang terbentuk akan terhidrolisis menjadi ion karboksilat dan etanol. Di samping itu keberadaan air dan asam lemak bebas juga menyebabkan terjadinya reaksi penyabunan dari trigliserida sebelum reaksi transesterifikasi berjalan sempurna. Menurut penelitian Venkanna dan Reddy (2009) menyatakan bahwa proses penyabunan akan berpengaruh terhadap produk yang dihasilkan, di mana terjadinya pembentukan sabun akan menyebabkan pemisahan gliserol menjadi sulit dan hilangnya etil ester.

Untuk meningkatkan rendamen campuran etil ester maka tahapan penelitian selanjutnya adalah melakukan variasi pengadukan dan variasi waktu. 
Rendemen etil ester yang dihasilkan kemudian dianalisis dengan gas kromatografi untuk mengetahui komposisi etil ester utamanya kandungan etil laurat. Di mana diketahui bahwa komponen terbesar dari minyak kelapa murni adalah kandungan asam laurat. Sehingga dengan mengetahui komposisi tersebut dapat dijadikan patokan untuk mengetahui kondisi optimum dari reaksi transesterifikasi.

\section{Pengaruh variasi pengadukan terhadap rendamen campuran etil ester}

Penggunaan variasi pengadukan bertujuan untuk mendapatkan rendemen maksimum dari etil ester asam lemak. Di mana diterapkan pengadukan 200 sampai $600 \mathrm{rpm}$.

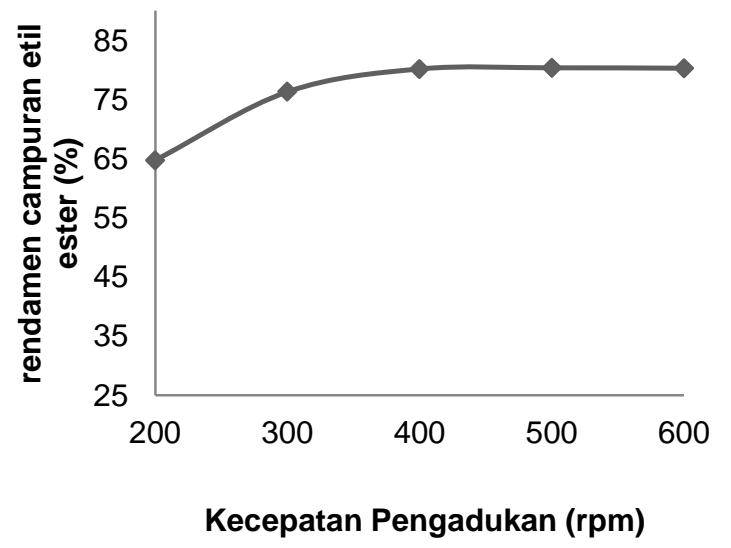
Gambar 5 Grafik hubungan variasi pengadukan terhadap rendemen etil ester.

Berdasarkan hasil penelitian menunjukkan bahwa rendemen etil ester yang dihasilkan meningkat (Gambar 5). Pada kecepatan pengadukan 200 rpm rendemen yang dihasilkan 64,72 \%, sedangkan pada kecepatan $300 \mathrm{rpm}$ rendemen yang dihasilkan 76,28\%.
Untuk kecepatan pengadukan di atas 400 rpm rendemen etil ester yang dihasilkan cenderung stabil kisaran $80 \%$. Adanya variasi pengadukan menyebabkan terjadinya tumbukan antara permukaan molekul tiap reaktan sehingga produk yang dihasilkan juga semakin meningkat. Campuran etil ester yang dihasilkan dianalisis menggunakan gas kromatografi, hal ini bertujuan untuk mengetahui komposisi etil ester utamanya konsentrasi etil laurat yang ada dalam campuran etil ester tersebut.

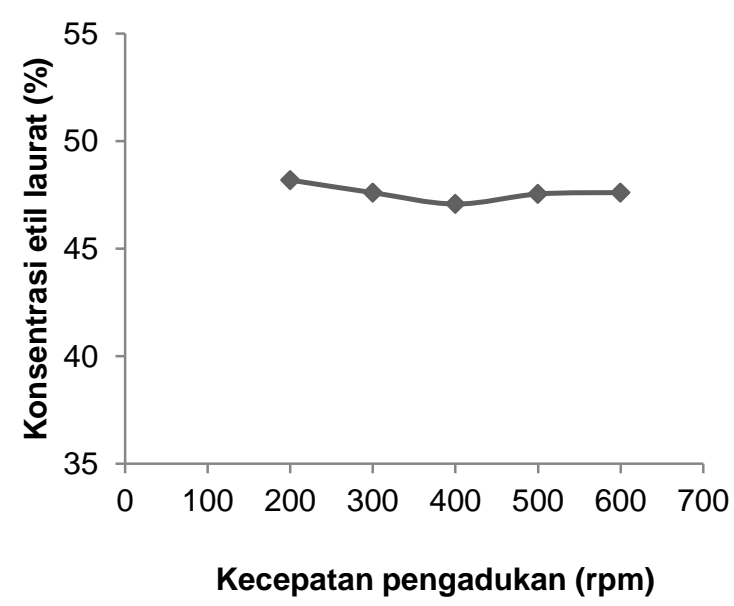

Gambar 6 Grafik hubungan variasi pengadukan terhadap komposisi etil laurat

Berdasarkan Gambar 6 hasil analisis gas kromatografi terhadap konsentrasi etil laurat untuk pengadukan 200 rpm yaitu 48,18 \% menunjukkan puncak yang tertinggi, kemudian pengadukan di atas $200 \mathrm{rpm}$ konsentrasi etil laurat cenderung stabil dengan konsentrasi kisaran $47 \%$. Hal ini berarti bahwa pengaruh pengadukan terhadap konsentrasi etil laurat tidak berpengaruh secara signifikan. 


\section{Pengaruh variasi waktu terhadap rendemen campuran etil ester}

Penggunaan variasi waktu bertujuan untuk mendapatkan rendemen maksimum dari campuran etil ester asam lemak. Dengan variasi waktu 20 menit sampai 60 menit.

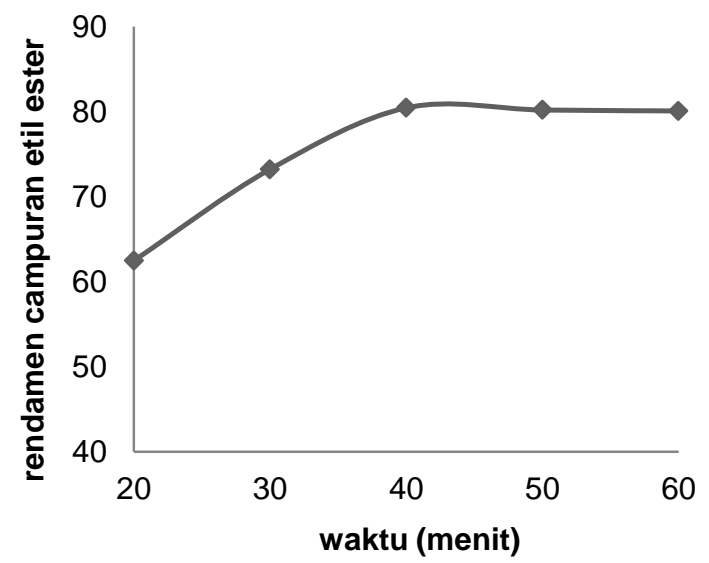

Gambar 7 Grafik hubungan variasi waktu terhadap rendemen etil ester

\section{Berdasarkan Gambar 7} menunjukkan bahwa pengaruh variasi waktu terhadap rendemen campuran etil ester yang dihasilkan meningkat seiring dengan waktu reaksi, namun demikian tingkat kesetimbangan waktu reaksi dalam suatu sistem reaksi memiliki batasan kesetimbangan sehingga etil ester yang terbentuk akan menurun. Hal ini dimungkinkan karena adanya pengaruh katalis $\mathrm{NaOH}$ yang bereaksi dengan asam lemak pada minyak kelapa mempengaruhi pembentukan gliserol sehingga terjadi reaksi saponifikasi dan kemungkinan terjadi reaksi hidrolisis kembali etil ester menjadi asam lemaknya. Hasil transesterifikasi campuran etil ester dianalisis dengan gas kromatografi untuk mengetahui konsentrasi etil laurat yang terkandung dalam campuran etil ester.

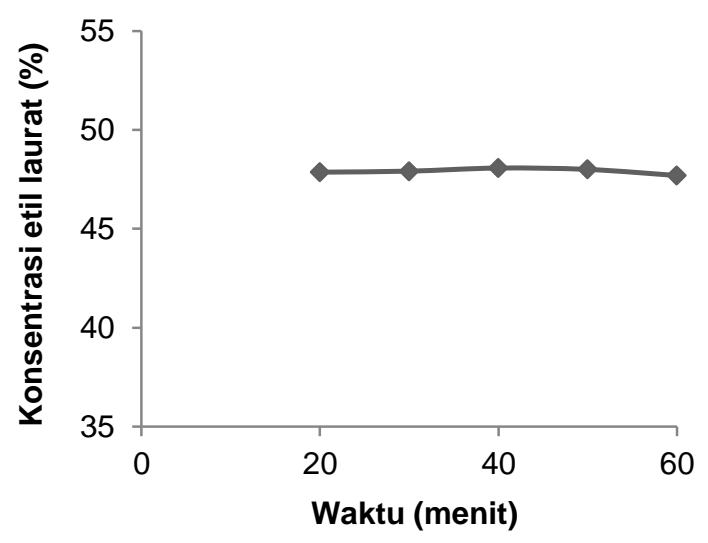

Gambar 8 Grafik hubungan variasi waktu terhadap konsentrasi etil laurat.

Berdasarkan Gambar 8 menunjukkan bahwa konsentrasi etil laurat tertinggi $48,05 \%$ pada variasi waktu 40 menit, sedangkan konsentrasi etil laurat terendah pada variasi waktu 60 menit yaitu 47,7 \%. Hal ini berarti bahwa perlakuan variasi waktu dalam proses transesterifikasi etil ester tidak terlalu berpengaruh secara signifikan terhadap konsentrasi etil laurat.

\section{Hasil analisis etil ester dengan GC dan GC-MS}

Hasil transesterifikasi berupa campuran etil ester dianalisis dengan GC dan GC-MS, sehingga diharapkan dapat diketahui jenis ester asam lemak yang terdapat dalam campuran etil ester tersebut. Berdasarkan hasil analisis menggunakan GC dan GC-MS dapat diketahui bahwa terdapat 11 puncak yang teridentifikasi sebagai campuran etil ester (Gambar 9). 


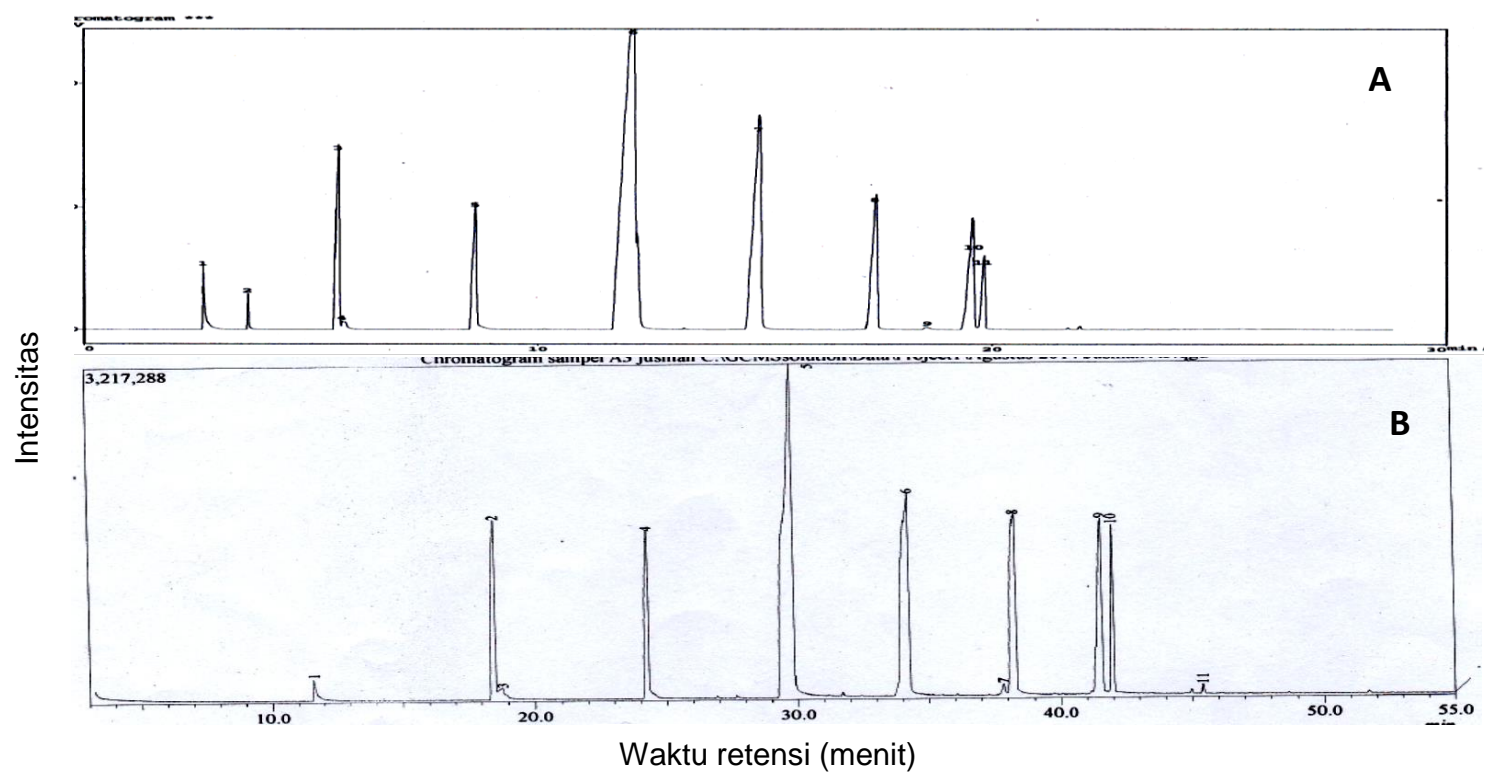

Gambar 9 Kromatogram GC (A) dan GC-MS (B) hasil transesterifikasi etil ester

Hal ini berarti bahwa campuran etil ester yang dihasilkan terdapat 11 senyawa, yang terdeteksi sebagai senyawa etil ester ada 9 puncak dan 2 puncak sebagai asam lemak minyak kelapa. Senyawa-senyawa tersebut berdasarkan data NIST (National Institute Standard Technology) dan Wiley Library.

Tabel 1 Hasil interpretasi kromatogram spektra massa GC-MS

\begin{tabular}{ccclcc}
\hline Puncak & $\begin{array}{c}\text { Waktu retensi } \\
\text { menit }\end{array}$ & \% relatif & \multicolumn{1}{c}{ Senyawa } & BM & \%SI \\
\hline 1 & 11,618 & 0,75 & Etil kaproat & 144 & 95 \\
2 & 18,502 & 8,37 & Etil kaprilat & 172 & 94 \\
3 & 18,792 & 0,51 & Asam kaprilat & 144 & 94 \\
4 & 24,304 & 7,42 & Etil kaprat & 200 & 94 \\
5 & 29,867 & 36,09 & Etil laurat & 228 & 95 \\
6 & 34,254 & 18,96 & Etil miristat & 256 & 93 \\
7 & 37,846 & 0,39 & Asam palmitat & 256 & 93 \\
8 & 38,292 & 11,58 & Etil palmitat & 284 & 94 \\
9 & 41,606 & 10,14 & Etil oleat & 310 & 92 \\
10 & 42,025 & 5,60 & Etil stearat & 312 & 94 \\
11 & 45,406 & 0,20 & Etil palmitat & 284 & 94 \\
\hline
\end{tabular}

Keterangan : \% Sl=\% kemiripan senyawa berdasarkan data NIST

\section{KESIMPULAN}

Berdasarkan uraian dari hasil dan pembahasan penelitian, maka dapat disimpulkan bahwa sintesis etil ester melalui proses transesterifikasi berlangsung pada kondisi rasio minyak
kelapa/etanol/NaOH perbandingan $1: 2$ : 0,02 (100 mL : $50 \mathrm{~mL}: 2$ gram) pada agitasi pengadukan $300 \mathrm{rpm}$, rendemen etil ester yang dihasilkan 76,48 \%. Konsentrasi etil ester yang dihasilkan melalui variasi pengadukan di atas 300 
rpm, dan waktu reaksi di atas 30 menit menghasilkan rendemen etil ester dengan kisaran $80 \%$. Hasil analisis menggunakan GC dan GC-MS dapat diketahui bahwa terdapat 11 puncak yang teridentifikasi sebagai campuran etil ester.

\section{DAFTAR PUSTAKA}

Cernoch, M., Hajek, M., Skopal, F. (2010). Ethanolysis of Rapeseed Oil : Distribution of Ethyl Ester, Glycerides, and Glycerol Between Ester and Glycerol Phases. Bioresour. Technol., 10: 2071-2075.

Darnoko, D., M. Cheryan. (2000). Kinetics of Palm Oil Transesterification in a Batch Reactor, J. Am. Oil Chem. Soc. 77: 1263-1267.

Freedman, B., E.H. Pryde, T.L Mounts. (1984). Variables affecting the yield of fatty esters from transesterified vegetable oils, J. Am. Oil Chem. Soc., 61(10): 1638-1643.

Freedman, B., R.O Butterfield, E.H. Pryde. (1986). Transesterification kinetics of soybean oil, J. Am. Oil Chem. Soc., 63 (10): 1375-1380.

Fukuda, H., Kondo, A., \& Noda, H. (2001). Biodiesel fuel production by transesterification of oils. Journal of bioscience and bioengineering, 92(5), 405-416.

Jusman, Setiaji, B., Triyonob, Syoufian, A. (2013). Fractionation Of Medium Chain Fatty Acid Ethyl Esters From Virgin Coconut Oil Via Transesterification and Distillation
Under Reduced Pressure. International Journal of Basic \& Applied Sciences IJBAS-IJENS. 13(1): 60-64.

Kucek, KT., A. Maria., Oliveira, F.C., M. Wilhelm H., Ramos, L P. (2007). Ethanolysis of Refined Soybean Oil Assisted by Sodium and Potassium Hydroxides. J. Am. Oil Chem. Soc., 84: 385-392.

Meneghetti, S.M.P., Meneghetti, M.R., Wolf, C.R., Silva, E.C., Coimbra, M.de A., Carvalho, H.V. (2006). Ethanolysis of Castor and Cottonseed Oil : A Systematic Study Using Classical Catalysts J. Am. Oil Chem. Soc., 83: 819-822.

Schuchardt, U., Sercheli, R., Vargas, R.M. (1998). Transesterification of vegetable oils: a review. J. Braz. Chem. Soc., 9: 199-210.

Tippayawong, N., Kongjareon, E., Jompakdee, W. (2005). Ethanolysis of Soybean Oil Into Biodiesel : Process Optimation Via Central Composite Design, J. Mech. Sci. Technol., 10 (19): 1902-1909.

Venkanna, BK., Reddy, C V. (2009). Biodiesel production and optimization from Calophyllum inophyllum linn oil (honne oil)--a three stage method. Bioresource Technology. 100(21): 5122-5125.

Zhou, W., Konar, S. K., Boocock, G. B. (2003). Ethyl esters from the singlephase base - catalyzed ethanolysis of vegetable oils. J. Am. Oil Cem. Soc. 80(4):367-371. 